\title{
Risk stratification of papillary thyroid microcarcinomas via an easy-to-use system based on tumor size and location: clinical and pathological correlations
}

\author{
EMŐKE-ANDREA SZÁSZ ${ }^{1}$, Adela CORINA NeCHIFOR-BOILA ${ }^{1,2)}$, ANCUTJA ElENA ZAHAN ${ }^{1}$, \\ TOADER SEPTIMIU VOIDĂZAN ${ }^{3}$, ANGELA BORDA ${ }^{1,4)}$ \\ 1) Department of Histology, George Emil Palade University of Medicine, Pharmacy, Science, and Technology of Târgu Mureş, \\ Romania \\ 2) Department of Pathology, Mureş County Hospital, Târgu Mureş, Romania \\ ${ }^{3)}$ Department of Epidemiology, George Emil Palade University of Medicine, Pharmacy, Science, and Technology of Târgu Mureş, \\ Romania \\ 4) Department of Pathology, Emergency County Hospital, Târgu Mureş, Romania
}

\begin{abstract}
Introduction: We aimed to determine whether two clinically accessible parameters, tumor size and location within the thyroid, correlate with clinicopathological features that are predictors of high risk in papillary thyroid microcarcinomas (PTMCs). Materials and Methods: PTMC cases were obtained from the database of the Department of Pathology, Emergency County Hospital, Târgu Mureş, Romania. Four tumor groups were created based on tumor size and location: Group I ( $\geq 5 \mathrm{~mm}$, subcapsular), Group II ( $\geq 5 \mathrm{~mm}$, nonsubcapsular), Group III ( $<5 \mathrm{~mm}$, subcapsular), and Group IV ( $<5 \mathrm{~mm}$, nonsubcapsular) PTMCs. Clinicopathological features and follow-up data were compared by univariate and multivariate analysis. Results: Our study included 164 PTMCs ( $n=70 / 20 / 19 / 55$ in Groups I/II/III/IV, respectively). High-grade morphological features, such as plump pink cells $(p=0.010)$, tumor desmoplasia $(p=0.022)$ and sclerosis $(p=0.001)$, infiltrative tumor borders $(p=0.005)$, positive resection margins $(p=0.005)$, invasion into the perithyroid adipose tissue $(p=0.001)$, irregular nuclear membranes $(p=0.004)$, and pseudoinclusions ( $p=0.001$ ) were significantly more prevalent among Group I PTMCs. Group IV PTMCs were characterized by a paucity of the above-mentioned morphological features, while Group II and III PTMCs displayed intermediate morphological profiles. Conclusions: Group I PTMCs proved to be associated with more aggressive morphological features and might need a more careful clinical approach.
\end{abstract}

Keywords: thyroid, microcarcinoma, tumor size, tumor location, risk stratification.

\section{口 Introduction}

Worldwide, the incidence of papillary thyroid carcinoma (PTC) has significantly increased over recent decades [1, 2]. There is agreement that small tumors, namely papillary thyroid microcarcinomas (PTMCs), are the main drivers of this increase [2-5]. While PTMCs accounted for $25 \%$ of all thyroid cancers in 1988-1989, 20 years later (2008-2009) this percentage reached 39\% [2,6] and later, in 2016, 47.5\% [7]. Many factors contribute to this rising incidence of PTMCs. Among them, increased surveillance of the general population, with the widespread use of neck ultrasound (US) examination and fine-needle aspiration (FNA) biopsy of the thyroid nodules, has played an important role $[1,8,9]$. Moreover, recent advances in sampling techniques and more careful examination of thyroid specimens resected for benign diseases have resulted in the detection of many PTMCs [10]. For all these reasons, PTMCs are responsible for a phenomenon referred to as thyroid cancer "overdiagnosis" [11-14] or as an "epidemic of diagnosis" [12].

PTMCs are commonly described as indolent cancers, harboring an excellent prognosis in the great majority of cases $[2,11]$. Nevertheless, some PTMCs are associated with extrathyroidal extension, lymph node metastasis, and tumor recurrence $[15,16]$. In line with this, controversies regarding the management of PTMCs have grown dramatically over recent years [3]. Based on the observation that PTMC is generally a harmless occult carcinoma, several studies from Japan have proposed active surveillance instead of immediate surgery as a safe, but effective choice for adequately selected low-risk PTMC patients [17]. More recently, in 2015, the American Thyroid Association (ATA) also recognized active surveillance as an alternative to thyroidectomy in patients with low-risk PTMCs [18]. As Miyauchi highlighted, low-risk PTMC refers to the absence of high-risk features, such as lymph node metastasis, extrathyroidal extension, FNA biopsy findings suggesting high-grade malignancy, growth progression, and location close to the recurrent laryngeal nerve [19]. Controversy still exists on how to appropriately manage this group of patients, as some PTMCs classified as low risk at the time of the initial surgery may later be associated with disease recurrence or with other features entailing a more aggressive behavior [20].

If surgical treatment is nevertheless indicated, lobectomy is a valid option for unifocal PTMCs and total

\footnotetext{
This is an open-access article distributed under the terms of a Creative Commons Attribution-NonCommercial-ShareAlike 4.0 International Public License, which permits unrestricted use, adaptation, distribution and reproduction in any medium, non-commercially, provided the new creations are licensed under identical terms as the original work and the original work is properly cited.
} 
thyroidectomy (without subsequent radioactive iodine [RAI] ablation) for multifocal and bilateral PTMCs, as well as for PTMCs harboring worrisome clinicopathological features (such as aggressive histological subtype, vascular invasion, extrathyroidal extension or lymph node involvement) [18]. The problem with these high-risk clinicopathological features is that they are all available only after surgery.

Recently, Tallini et al. [13] analyzed a series of 298 PTMCs, aiming to investigate whether the location of the PTMC foci within the thyroid (subcapsular versus nonsubcapsular) and the tumor size have a potential outcome on the risk stratification of patients with PTMC. The authors demonstrated that the tumor location (subcapsular versus nonsubcapsular) and tumor size ( $<5 \mathrm{~mm}$ versus $\geq 5 \mathrm{~mm}$ ) represent valuable morphological tools for the proper selection of patients for active surveillance. Based on these results, the authors proposed an easy, four-group risk stratification system that can be successfully applied to patients with PTMC before surgery.

\section{Aim}

With the study by Tallini et al. [13] as our starting point, we aimed to determine in our series of cases whether these two clinically accessible parameters, tumor size and location within the thyroid, correlate with clinicopathological features that are predictors of high risk in PTMCs and consequently whether they could have an impact on the clinical management of patients with PTMC.

\section{Materials and Methods}

\section{Case selection}

We performed a retrospective study on a series of PTMCs. All consecutive PTMC cases registered in the database of the Department of Pathology, Emergency County Hospital, Târgu Mureş, Romania, from 2003 (January) to 2014 (December) were reevaluated. Inclusion criteria were: $(i)$ cases with a histopathological (HP) diagnosis of PTMC and (ii) availability of HematoxylinEosin (HE)-stained slides for case review.

Clinical information (age at the time of the diagnosis, gender, and date and type of surgery), and biochemical, imaging, and HP data were obtained from medical records.

The Ethics Committee of the George Emil Palade University of Medicine, Pharmacy, Science, and Technology of Târgu Mureş approved the study. Informed agreement was obtained from all of the patients included in this study.

\section{Pathological data}

The corresponding HE-stained slides for all the cases were independently reexamined by three pathologists with a particular interest in thyroid pathology (EAS, ANB, and $\mathrm{AB})$. All controversial features were further discussed using a triple-headed microscope and a consensus was established.

The following pathological features were evaluated: tumor size; histological type (conventional, or variant of PTC); the tumor margins (well circumscribed [not encapsulated or encapsulated] versus infiltrative); the stromal reaction (sclerosis/desmoplasia/fibrosis versus absence of all these changes); the intratumoral lymphocytic infiltrate, presence of psammoma bodies, intratumoral multinucleated giant cells, or plump pink cells; nuclear features; distance from the tumor's edge to the thyroid capsule, used to assess the location of the tumor with regard to the thyroid capsule (subcapsular versus nonsubcapsular) (Figure 1, A and B) [13]; invasion into the perithyroid adipose tissue; multifocality, lymph node involvement; and surgical resection margin status.

The diagnosis of PTMC, as well as the histological tumor type (conventional versus variant of PTC), were defined in accordance with the World Health Organization (WHO) Classification of Tumors of Endocrine Organs ( $4^{\text {th }}$ edition, 2017) [21]. We defined PTMCs as PTCs smaller or equal to one centimeter in size, incidentally discovered (either on the thyroidectomy specimen or following a targeted FNA procedure performed for a clinically "silent" subcentimeter nodule) [13]. Tumorassociated stromal reactions were defined on a spectrum ranging from a paucicellular, thick, collagenized stroma (sclerosis) (Figure 1C), a plump fibroblastic proliferation in a loose myxoid stroma (desmoplasia), or collagenous, non-myxoid stroma (fibrosis) (Figure 1D) at one end of the spectrum, and a lack of all these changes at the other end [22]. Plump pink cells were defined as polygonal tumor cells with nuclear features of PTC and moderate to abundant homogenous, eosinophilic cytoplasm; the plump cells differed from the cells associated with a diagnosis of tall cell PTC variant as their height was less than twice their width (were not "tall enough") [22]. To establish the nuclear grade of the tumor, the following nuclear features were assessed: enlargement, overlapping (size and shape), irregular contours, grooves, pseudoinclusions (nuclear membrane irregularities), and chromatin clearing (Figure 1, E and F). As in the nuclear score used to assist diagnosis of noninvasive follicular thyroid neoplasms with papillary-like nuclear features (NIFTP) [23], nuclear enlargement together with overlapping alone were considered low-grade nuclear features (present in all PTMC cases in our study), whereas the combined presence of nuclear membrane irregularities and chromatin clearing warranted a higher nuclear score and were thus regarded as high-grade nuclear features. Multifocality was defined when at least two separate tumor foci were identified in the same or contralateral thyroid lobe. Lymph node involvement was considered when tumor cells were identified in regional lymph nodes.

Based on relevant literature [13, 22, 24-26], histology consistent with a rare variant of PTC (tall cell, oncocytic, or Warthin-like), tumor sclerosis and desmoplasia, presence of plump pink cells, infiltrative tumor borders, invasion into the perithyroid adipose tissue, multifocality, lymph node involvement, and positive resection margins were considered to be high-risk morphological features.

The distance from the tumor's edge to the thyroid capsule and the tumor diameter were carefully measured on the HE-stained sections under the microscope (Olympus BX46 Olympus BX46, Olympus Life Science, Waltham, Massachusetts, USA) at a low magnification $(\times 40)$. The thyroid "capsule" was considered to be the thin, fibrous, peripheral layer separating the gland from its surrounding adipose stroma [27].

By applying the methodology of Tallini et al. [13], we 
divided our series of cases into four study groups, as follows:

- Group I: large subcapsular PTMCs of $\geq 5 \mathrm{~mm}$, and distance from the tumor's edge to the thyroid capsule -0 $\mathrm{mm}$;

- Group II: large nonsubcapsular PTMCs of $\geq 5 \mathrm{~mm}$, and distance from the tumor's edge to the thyroid capsule $>0 \mathrm{~mm}$;
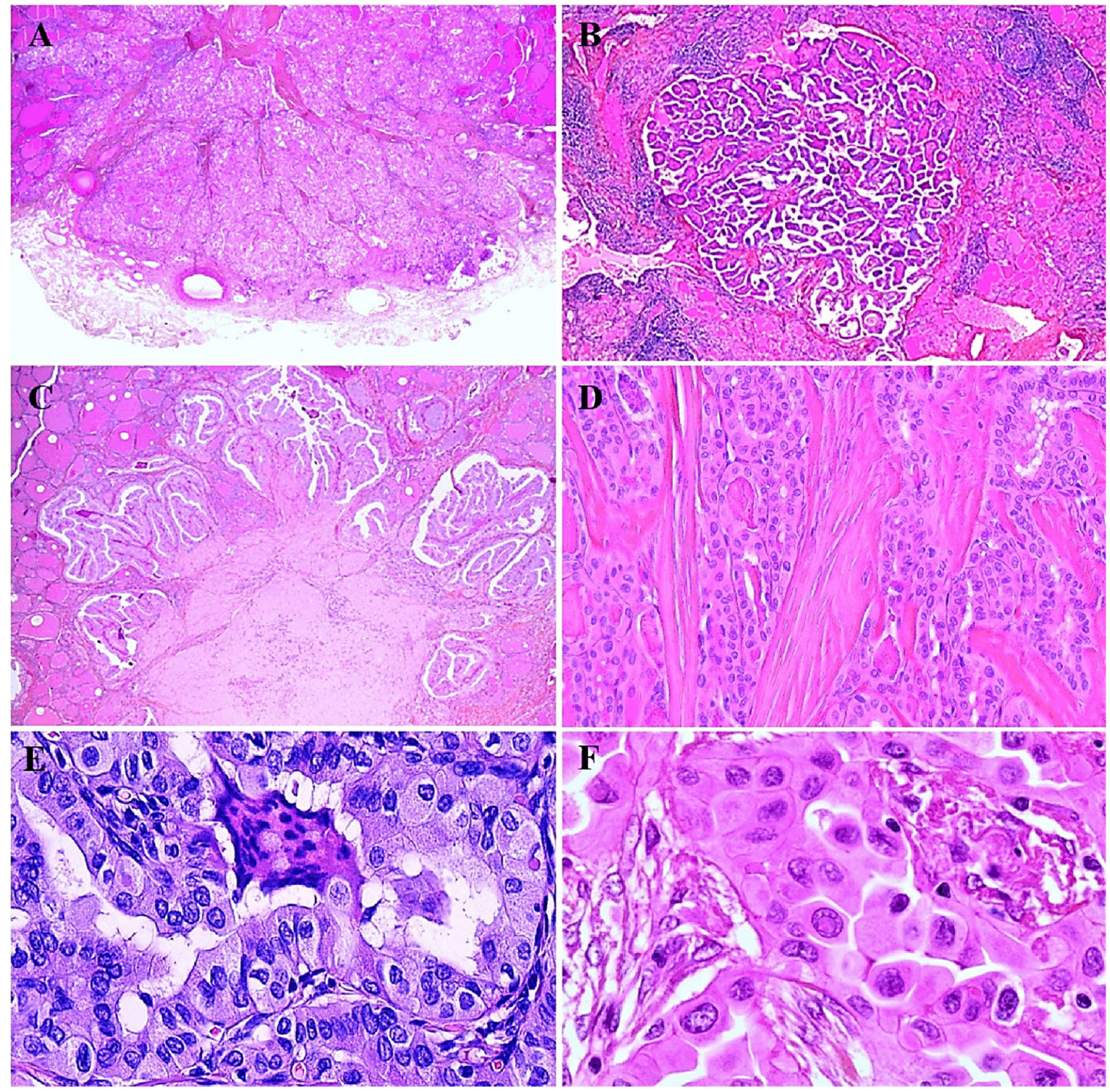

- Group III: small subcapsular PTMCs of $<5 \mathrm{~mm}$, and distance from the tumor's edge to the thyroid capsule -0 $\mathrm{mm}$

- Group IV: small nonsubcapsular PTMCs of $<5 \mathrm{~mm}$, and distance from the tumor's edge to the thyroid capsule $>0 \mathrm{~mm}$.

All pathological features, as well as relevant follow-up data, were compared between these four groups.

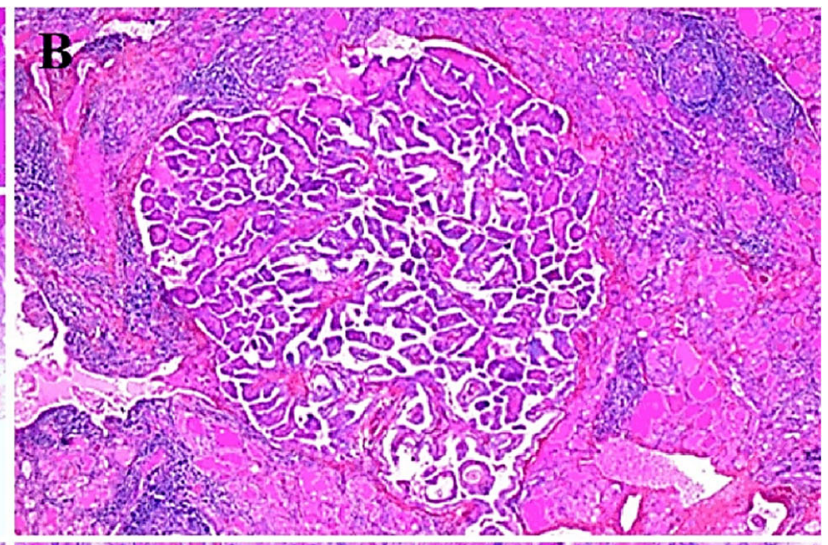

Figure 1 - Morphological features of the PTMCs in our study: (A) Group I (large $\geq 5 \mathrm{~mm}$, subcapsular) PTMC with infiltrative tumor borders and invasion into the perithyroid tissue; (B) Group IV (small $<5 \mathrm{~mm}$, nonsubcapsular) PTMC, not encapsulated, well circumscribed; Tumor-associated stromal reaction consistent with sclerosis (C) and fibrosis (D); (E) High-grade nuclear features in a Group I PTMC and intratumoral multinucleated giant cells; (F) Plump pink cells defined as polygonal-shape cells, with homogenous, eosinophilic, abundant cytoplasm and high-grade nuclear features, including pseudoinclusions. HE staining: $(A) \times 25$; $(B) \times 4$; $(C$ and $D) \times 100 ;(E$ and $F) \times 400$. HE: Hematoxylin-Eosin; PTMC: Papillary thyroid microcarcinoma.

\section{Follow-up data}

The follow-up included the time interval starting from the initial surgical treatment up to last oncological examination (January 2005 to December 2017). Data were obtained from the medical records of the patients registered in the Department of Nuclear Medicine, Prof. Dr. Ion Chiricuţă Oncological Institute, Cluj-Napoca, Romania.

The follow-up data consisted of: RAI (if received), basal and stimulated serum levels of thyroglobulin (Tg), thyroid-stimulating hormone (TSH) and Tg antibodies 
levels, US evaluation of the cervical region, and wholebody scans (WBS). On the basis of these data, the disease status of the patients was set in accordance with the 2009 [28] and 2015 [18] ATA risk of recurrence stratification system, as follows: disease free (residual disease absent on WBS and US, and low serum levels of basal and stimulated $\mathrm{Tg}$ ), persistent disease (presence of a detectable residual or metastatic tumor on WBS or US, and/or elevated serum levels of basal and stimulated $\mathrm{Tg}$ ), and recurrent disease (new biochemical disease or tumor recurrence in patients previously classified as disease free).

\section{Statistical analysis}

Statistical Package for Social Sciences (SPSS, version 20, Chicago, IL, USA) and GraphPad Prism 5 (GraphPad Software, San Diego, CA, USA) software were used for statistical assessment of the data. Data were labeled as nominal or quantitative variables. The KolmogorovSmirnov test was applied to test for normality of distribution of the quantitative variables; the quantitative variables were described by median and percentiles $(25-75 \%)$ or mean \pm standard deviation (SD), depending on the case. Analysis of variance (ANOVA) method was used to test differences between categories for variables with a normal distribution of variances, and Kruskal-Wallis analysis for non-normally distributed variables, respectively. The Bonferroni-Dunn correction was used for post hoc comparisons between pairs of categories. The association between nominal variables, that were described as absolutes and relative frequencies (\%), was analyzed by Pearson's $\chi^{2}$ (chi-squared) test. Odds ratio (OR) expressed with 95\% confidence intervals (CI) was used to quantify the size effect for statistically significant associations.

The relationship between PTMC groups and variables was analyzed using univariate and multivariate conditional logistic regression models. A backward-stepwise approach was applied for model building and Wald chi-squared analysis was the term significance test. We included as independent variables the data that achieved significance at $p<0.05$ in univariate analysis. Univariate and multivariate logistic regression analysis was performed for biomarkers and ORs were displayed. Two-tailed tests of significance were used for all $p$-values; statistically significant values of $p$ were considered $<0.05$. A forest plot was created to illustrate the most important results of the multivariate analysis in a single graphic.

\section{ㅁ Results}

\section{Clinical, pathological, and follow-up data}

Our study comprised 164 patients with PTMC who fulfilled the inclusion criteria. Table 1 summarizes their clinical, pathological, and follow-up data.

The mean age at diagnosis was $51.5 \pm 10.4$ years old and most cases occurred in women $(n=148 / 164,90.2 \%)$. Half of the PTMC cases were conventional PTMCs ( $n=79 / 164,48.2 \%$ ), closely followed by the follicular variant of PTMCs $(n=70 / 164,42.7 \%)$. Fifteen $(9.2 \%)$ PTMCs were rare variants of PTC (oncocytic, tall cell, or Warthin-like). Tumor invasion into the perithyroid adipose tissue was documented in 15 PTMCs (24.6\%). Lymph node dissection was performed in only 11 cases $(6.7 \%)$ Of these, four cases displayed lymph node involvement.
Table 1 - Clinical, pathological and follow-up data for

164 patients with PTMC included in the study

\begin{tabular}{c}
\hline Clinical, pathological and follow-up data \\
\hline Demographic data
\end{tabular}

\begin{tabular}{|c|c|}
\hline Age at diagnosis (mean $\pm S D$, years) & $51.5 \pm 10.4$ \\
\hline Female gender $(n, \%)$ & $148(90.2)$ \\
\hline \multicolumn{2}{|c|}{ Pathological features } \\
\hline
\end{tabular}

\begin{tabular}{ll}
\hline Conventional PTMC $(n, \%)$ & $79(48.2)$ \\
\hline Follicular variant of PTMC $(n, \%)$ & $70(42.7)$
\end{tabular}

Other variants of PTMC (tall cell, oncocytic, $15(9.2)$

Warthin-like) $(n, \%)$

Tumor size (mean \pm SD, mm) $\quad 4.97 \pm 2.7$

Distance from the tumor's edge to the thyroid $\quad 1.48 \pm 1.47$

capsule $(\mathrm{mm})$

Lymph node involvement $^{a}(n, \%) \quad 4 / 11$ (36.4)

\begin{tabular}{ll}
\hline Infiltrative tumor borders $(n, \%)$ & $84(51.2)$ \\
\hline
\end{tabular}

Invasion into the perithyroid adipose tissue $(n, \%) \quad 15(24.6)$

\begin{tabular}{ll}
\hline \multicolumn{2}{c}{ Type of surgery } \\
\hline Lobectomy $(n, \%)$ & $4(2.4)$
\end{tabular}

Total thyroidectomy $(n, \%) \quad 149(90.8)$

Total thyroidectomy with lymph node dissection 11 (6.7)

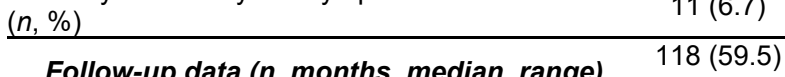

\begin{tabular}{lc} 
Follow-up data (n, months, median, range) & $\begin{array}{c}118(59.5) \\
{[18-135]}\end{array}$ \\
\hline 31 I therapy $(n, \%)$ & $95(80.5)$ \\
\hline Disease free $(n, \%)$ & $117(99.1)$ \\
\hline Persistent disease $(n, \%)$ & $1(0.8)$ \\
\hline Recurrent disease $(n, \%)$ & $0(0.0)$ \\
\hline
\end{tabular}

1311: lodine-131; $n$ : No. of cases; PTMC: Papillary thyroid microcarcinoma; SD: Standard deviation. ${ }^{a}$ Only cases with lymph node dissection are included ( $n$ with lymph node metastasis/ $n$ with lymph node dissection).

Most patients were treated by total thyroidectomy $(n=149 / 164,90.8 \%)$. We obtained follow-up information for $118(71.9 \%)$ patients; the median follow-up time interval was 59.5 months (range 18-135 months). Most of the patients received RAI therapy ( $n=95 / 118,80.5 \%)$; this was in accordance with the 2009 (28) ATA Guidelines for the management of patients with thyroid cancer followed by the Department of Nuclear Medicine, Prof. Dr. Ion Chiricuţă Oncological Institute, Cluj-Napoca, during the study period. At the last clinical assessment, all patients were disease free, apart from one for whom persistent disease occurred 94 months after the initial surgery. This case corresponded to an $8 \mathrm{~mm}$ subcapsular PTMC with infiltrative tumor borders.

\section{Tumor size and location within the thyroid}

The mean tumor size and the mean distance from the tumor's edge to the thyroid capsule for included PTMCs were $4.97 \pm 2.7 \mathrm{~mm}$ and $1.48 \pm 1.47 \mathrm{~mm}$, respectively.

Based on these two parameters, all patients were categorized into the four study groups described in the "Materials and Methods" section, as follows: Group I, $n=70$; Group II, $n=20$; Group III, $n=19$; and Group IV, $n=55$.

Clinical, pathological, and follow-up data were analyzed for each case and within each of the four groups; the data were then compared between these four groups by univariate analysis to estimate their possible relevance for risk stratification of patients. Table 2 summarizes the results. 
Table 2 - Univariate analysis comparing the clinical, morphological and follow-up data between the four PTMC groups

\begin{tabular}{|c|c|c|c|c|c|}
\hline Variables & $\begin{array}{c}\text { Group I } \\
\text { Subcapsular, } \\
\geq 5 \mathrm{~mm}(n=70)\end{array}$ & $\begin{array}{c}\text { Group II } \\
\text { Nonsubcapsular, } \\
\geq 5 \mathrm{~mm}(n=20)\end{array}$ & $\begin{array}{c}\text { Group III } \\
\text { Subcapsular, } \\
<5 \mathrm{~mm}(n=19) \\
\end{array}$ & $\begin{array}{c}\text { Group IV } \\
\text { Nonsubcapsular, } \\
<5 \mathrm{~mm}(n=55)\end{array}$ & $p$-value \\
\hline \multicolumn{6}{|c|}{ Demographic features } \\
\hline Age (mean $\pm S D$, years) & $51.2 \pm 10.0$ & $51.6 \pm 11.5$ & $51.1 \pm 7.7$ & $52.0 \pm 11.5$ & 0.920 \\
\hline Female gender $(n=148)$ & $65(92.9)$ & $17(85.0)$ & $16(84.2)$ & $80(90.9)$ & 0.580 \\
\hline \multicolumn{6}{|c|}{ Pathological features } \\
\hline Histological variant & & & & & 0.012 \\
\hline Conventional $(n=79)$ & $41(58.6)$ & $3(15.0)$ & $8(42.1)$ & $27(49.1)$ & \\
\hline Follicular $(n=70)$ & $20(28.6)$ & $14(70.0)$ & $10(52.6)$ & $26(47.3)$ & \\
\hline Tall cell $(n=1)$ & $0(0.0)$ & $1(5.0)$ & $0(0.0)$ & $0(0.0)$ & \\
\hline Oncocytic $(n=7)$ & $4(5.7)$ & $1(5.0)$ & $1(5.3)$ & $1(1.8)$ & \\
\hline Warthin-like $(n=7)$ & $5(7.1)$ & $1(5.0)$ & $0(0.0)$ & $1(1.8)$ & \\
\hline \multicolumn{6}{|l|}{ Nuclear features } \\
\hline Nuclear enlargement $(n=164)$ & $70(100.0)$ & $20(100.0)$ & $19(100.0)$ & $55(100.0)$ & 0.950 \\
\hline Overlapping $(n=158)$ & $67(95.7)$ & $19(95.0)$ & $19(100.0)$ & $53(96.4)$ & 0.890 \\
\hline Irregular nuclear membranes $(n=164)$ & $67(95.7)$ & $17(85.0)$ & $16(84.2)$ & $42(76.4)$ & 0.019 \\
\hline Grooves $(n=163)$ & $70(100.0)$ & $20(100.0)$ & $19(100.0)$ & $54(98.2)$ & 0.570 \\
\hline Chromatin clearing $(n=158)$ & $69(98.6)$ & $17(85.0)$ & $19(100.0)$ & $53(96.4)$ & 0.037 \\
\hline Pseudoinclusions $(n=72)$ & $44(62.9)$ & $8(40.0)$ & $6(31.6)$ & $14(25.5)$ & $<0.001$ \\
\hline Plump pink cells $(n=40)$ & $25(35.7)$ & $2(10.0)$ & $5(26.3)$ & $8(14.5)$ & 0.016 \\
\hline \multicolumn{6}{|l|}{ Tumor-associated stromal reaction } \\
\hline None $(n=63)$ & $17(24.3)$ & $12(60.0)$ & $8(42.1)$ & $26(38.4)$ & $<0.001$ \\
\hline Fibrosis $(n=57)$ & $17(24.3)$ & $7(35.0)$ & $9(47.4)$ & $24(43.6)$ & \\
\hline Desmoplasia $(n=18)$ & $13(18.6)$ & $1(5.0)$ & $2(10.5)$ & $2(3.6)$ & \\
\hline Sclerosis $(n=26)$ & $23(32.9)$ & $0(0.0)$ & $0(0.0)$ & $3(5.5)$ & \\
\hline Psammoma bodies $(n=20)$ & $13(18.6)$ & $3(15.0)$ & $1(5.3)$ & $3(5.5)$ & 0.100 \\
\hline Intratumoral lymphocytic infiltrate $(n=39)$ & $15(21.4)$ & $2(10.0)$ & $5(26.3)$ & $17(30.9)$ & 0.270 \\
\hline Intratumoral multinucleated giant cells $(n=26)$ & $20(28.6)$ & $1(5.0)$ & $1(5.3)$ & $4(7.3)$ & 0.001 \\
\hline \multicolumn{6}{|l|}{ Tumor borders } \\
\hline $\begin{array}{l}\text { Well-circumscribed, non-encapsulated } \\
(n=53)\end{array}$ & $20(28.6)$ & $7(35.0)$ & $7(36.8)$ & $19(34.5)$ & 0.005 \\
\hline Encapsulated $(n=27)$ & $3(4.3)$ & $6(30.0)$ & $5(26.3)$ & $13(23.6)$ & \\
\hline Infiltrative $(n=84)$ & $47(67.1)$ & $7(35.0)$ & $7(36.8)$ & $23(41.8)$ & \\
\hline Multifocality $(n=43)$ & $19(72.9)$ & $8(40.0)$ & $4(21.1)$ & $12(21.8)$ & 0.430 \\
\hline Positive resection margins $(n=9)$ & $9(12.9)$ & $0(0.0)$ & $0(0.0)$ & $0(0.0)$ & 0.005 \\
\hline $\begin{array}{l}\text { Invasion into the perithyroid adipose tissue } \\
(n=15)\end{array}$ & $12(17.1)$ & $0(0.0)$ & $3(15.8)$ & $0(0.0)$ & 0.004 \\
\hline Lymph node metastasis $(n=4)^{\star}$ & $3 / 10$ & $0 / 0$ & $1 / 1$ & $0 / 0$ & 0.476 \\
\hline \multicolumn{6}{|c|}{ Follow-up data } \\
\hline Administration of RAI $(n=95)$ & $42(80.8)$ & $11(73.3)$ & $11(84.6)$ & $31(83.8)$ & 0.820 \\
\hline $\begin{array}{l}\text { Unfavorable disease-related events } \\
\text { (persistent disease) }(n=1)\end{array}$ & $1(1.9)$ & $0(0.0)$ & $0(0.0)$ & $0(0.0)$ & 0.950 \\
\hline
\end{tabular}

$n$ : No. of cases; PTMC: Papillary thyroid microcarcinoma; RAI: Radioactive iodine. Statistically significant differences are shown in bold and italics. *Data regarding only cases with lymph node dissection (10 cases Group I and one case Group III) - $n$ with lymph node metastasis/ $n$ with lymph node dissection.

Group I PTMCs (large $\geq 5 \mathrm{~mm}$, subcapsular) were significantly associated with conventional histology $(p=0.012)$; high-grade nuclear features, such as irregular nuclear membranes $(p=0.019)$, chromatin clearing $(p=0.037)$, and pseudoinclusions $(p<0.001)$; the presence of plump pink cells $(p=0.016)$; tumor sclerosis $(p=0.0001)$; the presence of intratumoral multinucleated giant cells $(p=0.001)$; infiltrative tumor borders $(p=0.005)$, positive surgical margins $(p=0.005)$; and tumor invasion into the perithyroid adipose tissue $(p=0.004)$. Out of the four patients with PTMC who had documented lymph node metastasis, three had PTMCs that had been classified as Group I. The only patient in our study with an unfavorable follow-up event (persistent disease) also had PTMC that had been classified as Group I.
While high-risk morphological features were significantly prevalent among Group I PTMCs, Group IV PTMCs (small $<5 \mathrm{~mm}$, nonsubcapsular) revealed a completely different morphological profile. Almost half of the cases were PTMCs, follicular variant (47.3\%). Unlike Group I PTMCs, Group IV PTMCs were characterized by a scarcity of tumor-associated stromal reactions (desmoplasia 3.6\% or sclerosis $5.5 \%$ ), plump pink cells (14.5\%), and nuclear pseudoinclusions (25.5\%).

Group II (large $\geq 5 \mathrm{~mm}$, nonsubcapsular) and III (small $<5 \mathrm{~mm}$, subcapsular) PTMCs revealed a morphological profile somewhere between those of Group I and Group IV PTMCs. In these groups, most PTMCs were of the follicular variant ( $70.0 \%$ and $52.6 \%$, respectively). Stromal reactions were absent in $60 \%$ of the PTMCs in Group II 
and in $42.1 \%$ of PTMCs in Group III. Only a few cases displayed plump pink cells $(10.0 \%$ Group II and $26.3 \%$ Group III). One patient with a PTMC classified as Group III had lymph node metastasis, and three PTMCs in Group III exhibited tumor invasion into the perithyroid adipose tissue.

Table 3 -Multivariate analysis comparing the pathological features between the four PTMCs

\begin{tabular}{|c|c|c|c|c|c|c|c|c|c|}
\hline \multirow{2}{*}{ Variables } & \multicolumn{3}{|c|}{$\begin{array}{c}\text { Group I } \\
\text { Subcapsular, } \geq 5 \mathrm{~mm}\end{array}$} & \multicolumn{3}{|c|}{$\begin{array}{c}\text { Group II } \\
\text { Nonsubcapsular, } \geq 5 \mathrm{~mm}\end{array}$} & \multicolumn{3}{|c|}{$\begin{array}{c}\text { Group III } \\
\text { Subcapsular, }<5 \mathrm{~mm}\end{array}$} \\
\hline & OR & p-value & $95 \% \mathrm{Cl}$ & OR & p-value & $95 \% \mathrm{Cl}$ & $O R$ & p-value & $95 \% \mathrm{Cl}$ \\
\hline \multicolumn{10}{|l|}{ Histological variant } \\
\hline Conventional variant & 1.14 & 0.033 & $1.01-2.93$ & 2.60 & 0.086 & $0.87-7.76$ & 1.24 & 0.680 & $0.43-3.52$ \\
\hline Follicular variant & 1.27 & 0.180 & $0.15-2.54$ & 2.54 & 0.950 & $0.12-3.56$ & 0.34 & $<0.001$ & $0.12-0.68$ \\
\hline Other variants $^{a}$ & 91 & 0.090 & $0.81-18.9$ & 2.94 & 0.290 & $0.38-22.4$ & 1.47 & 0.750 & $0.12-17.22$ \\
\hline \multicolumn{10}{|l|}{ Nuclear features } \\
\hline Irregular nuclear mer & 6.91 & 0.004 & $1.85-25.70$ & 1.75 & 0.420 & $0.40-6.94$ & 1.65 & 0.470 & $0.41-6.57$ \\
\hline Chromatin clearing & 2.60 & 0.440 & $0.23-29.48$ & 0.21 & 0.100 & $0.03-1.38$ & 5.79 & 0.960 & $0.11-7.58$ \\
\hline Pseudoinclusions & 4.95 & 0.001 & $2.28-10.77$ & 1.95 & 0.220 & $0.66-5.75$ & 1.35 & 0.600 & $0.43-4.23$ \\
\hline Plump pink cells & 3.26 & 0.010 & $1.33-7.98$ & 0.65 & 0.610 & $0.12-3.37$ & 2.098 & 0.250 & $0.59-7.44$ \\
\hline \multicolumn{10}{|l|}{ Tumor-associated stromal reaction } \\
\hline None & 0.35 & 0.008 & $0.16-0.76$ & 1.67 & 0.330 & $0.59-4.73$ & 0.81 & 0.690 & $0.28-2.32$ \\
\hline Fibrosis & 0.41 & 0.024 & $0.19-0.81$ & 0.69 & 0.500 & $0.24-2.01$ & 1.16 & 0.770 & $0.40-3.31$ \\
\hline Desmoplasia & 6.04 & 0.022 & $1.30-28.05$ & 1.39 & 0.790 & $0.12-16.27$ & 3.11 & 0.270 & $0.40-23.84$ \\
\hline Sclerosis & 8.48 & 0.001 & $2.39-30.08$ & 0.56 & 0.960 & $0.12-12.40$ & 0.58 & 0.950 & $0.11-12.50$ \\
\hline Intratumoral multinucleated giant cells & 5.10 & 0.005 & $1.62-15.98$ & 0.67 & 0.73 & $0.07-6.39$ & 0.70 & 0.760 & $0.07-6.76$ \\
\hline Infiltrative tumor borders & 2.84 & 0.005 & $1.36-5.91$ & 2.60 & 0.086 & $0.87-7.76$ & 1.24 & 0.680 & $0.43-3.52$ \\
\hline Positive resection margins & 4.50 & 0.005 & $1.03-30.70$ & 0.36 & $<0.001$ & $0.12-0.85$ & 0.34 & $<0.001$ & $0.11-0.68$ \\
\hline $\begin{array}{l}\text { Invasion into the perithyro } \\
\text { tissue }\end{array}$ & 5.36 & 0.001 & $1.37-41.50$ & 0.36 & $<0.001$ & $0.14-0.63$ & 5.55 & 0.980 & $0.63-6.89$ \\
\hline
\end{tabular}

Cl: Confidence interval; OR: Odds ratios; PTMCs: Papillary thyroid microcarcinomas. Statistically significant differences are shown in bold and

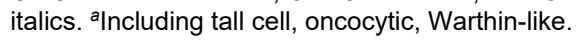

Table 4 -Multivariate analysis comparing the pathological features between the four PTMC groups, considering Group I (subcapsular, $\geq 5 \mathrm{~mm}$ ) as reference

\begin{tabular}{|c|c|c|c|c|c|c|c|c|c|}
\hline \multirow{2}{*}{ Variables } & \multicolumn{3}{|c|}{$\begin{array}{c}\text { Group II } \\
\text { Nonsubcapsular, } \geq 5 \mathrm{~mm}\end{array}$} & \multicolumn{3}{|c|}{$\begin{array}{c}\text { Group III } \\
\text { Subcapsular, }<5 \mathrm{~mm}\end{array}$} & \multicolumn{3}{|c|}{$\begin{array}{c}\text { Group IV } \\
\text { Nonsubcapsular, }<5 \mathrm{~mm}\end{array}$} \\
\hline & OR & p-value & $95 \% \mathrm{Cl}$ & OR & p-value & $95 \% \mathrm{Cl}$ & OR & p-value & $95 \% \mathrm{Cl}$ \\
\hline \multicolumn{10}{|l|}{ Histological variant } \\
\hline Conventional variant & 5.83 & 0.001 & $1.96-17.31$ & 2.77 & 0.054 & $0.98-7.85$ & 2.24 & 0.033 & $1.07-4.70$ \\
\hline Follicular variant & 5.90 & 0.980 & $0.01-5.47$ & 0.27 & 0.010 & $0.12-0.96$ & 0.77 & 0.180 & $0.25-4.58$ \\
\hline Other variants ${ }^{a}$ & 0.75 & 0.730 & $0.15-3.80$ & 0.38 & 0.370 & $0.05-3.17$ & 0.25 & 0.090 & $0.05-1.23$ \\
\hline \multicolumn{10}{|l|}{ Nuclear features } \\
\hline Irregular nuclear me & 0.25 & 0.110 & $0.05-1.37$ & 0.24 & 0.097 & $0.04-1.29$ & 0.14 & 0.004 & $0.04-0.54$ \\
\hline Chromatin clearing & 0.08 & 0.035 & $0.01-0.84$ & 4.44 & 0.950 & $0.12-6.84$ & 0.38 & 0.440 & $0.03-4.34$ \\
\hline Pseudoinclusions & 0.39 & 0.073 & $0.14-1.09$ & 0.27 & 0.020 & $0.09-0.80$ & 0.20 & 0.001 & $0.09-0.44$ \\
\hline Plump pink cells & 0.22 & 0.041 & $0.04-0.93$ & 0.64 & 0.440 & $0.20-1.99$ & 0.30 & 0.010 & $0.12-0.75$ \\
\hline \multicolumn{10}{|l|}{ Tumor-associated stromal reaction } \\
\hline None & 0.21 & 0.004 & $0.08-0.61$ & 0.44 & 0.13 & $0.15-1.27$ & 0.35 & 0.008 & $0.16-0.76$ \\
\hline Fibrosis & 1.68 & 0.340 & $0.57-4.88$ & 2.80 & 0.06 & $0.97-8.04$ & 2.41 & 0.024 & $1.12-5.17$ \\
\hline Desmoplasia & 0.23 & 0.170 & $0.03-1.88$ & 0.51 & 0.41 & $0.10-2.51$ & 0.16 & 0.022 & $0.04-0.79$ \\
\hline Sclerosis & 0.02 & 0.980 & $0.02-12.50$ & 0.10 & 0.95 & $0.10-5.78$ & 0.11 & 0.001 & $0.03-0.41$ \\
\hline Intratumoral multinucleated giant cells & 0.13 & 0.056 & $0.02-1.05$ & 0.14 & 0.06 & $0.02-1.11$ & 0.19 & 0.005 & $0.06-0.61$ \\
\hline Infiltrative tumor borders & 5.44 & 0.002 & $1.81-16.10$ & 2.59 & 0.071 & $0.92-7.30$ & 2.09 & 0.049 & $1.00-4.36$ \\
\hline Positive resection margins & 0.56 & 0.950 & $0.12-6.23$ & 0.89 & 0.950 & $0.12-6.25$ & 0.62 & 0.960 & $0.42-2.54$ \\
\hline $\begin{array}{l}\text { Invasion into the perithyroic } \\
\text { tissue }\end{array}$ & 0.56 & 0.940 & $0.12-2.35$ & 0.90 & 0.890 & $0.22-3.60$ & 0.95 & 0.950 & $0.12-2.35$ \\
\hline
\end{tabular}

CI: Confidence interval; OR: Odds ratios; PTMC: Papillary thyroid microcarcinoma. Statistically significant differences are shown in bold and italics. Including tall cell, oncocytic, Warthin-like.

Unlike those in Group IV, Group I PTMCs independently correlated with the following pathological features: conventional histology $(p=0.033)$; high-grade nuclear features, such as irregular membranes $(p=0.004)$ and pseudoinclusions ( $p=0.001$ ); presence of plump pink cells $(p=0.010)$, tumor desmoplasia $(p=0.022)$ and sclerosis $(p=0.001)$, and intratumoral multinucleated giant cells $(p=0.005)$; infiltrative tumor borders $(p=0.005)$; positive 
resection margins $(p=0.005)$; and invasion into the perithyroid adipose tissue $(p=0.001)$ (Table 3$)$. Although not reached statistical significance, because of the low number of cases, multinomial logistic regression analysis also revealed that the rare PTC variants (tall cell, oncocytic, Warthin-like) were more likely to be found in Group I than in the other groups (OR: 3.91, 95\% CI: 0.81-18.9, $p=0.090$ ). Figure 2 illustrates the abovementioned results, summarizing the multivariate analysis when Group IV, the most indolent PTMC group was used as the reference for statistical analysis.

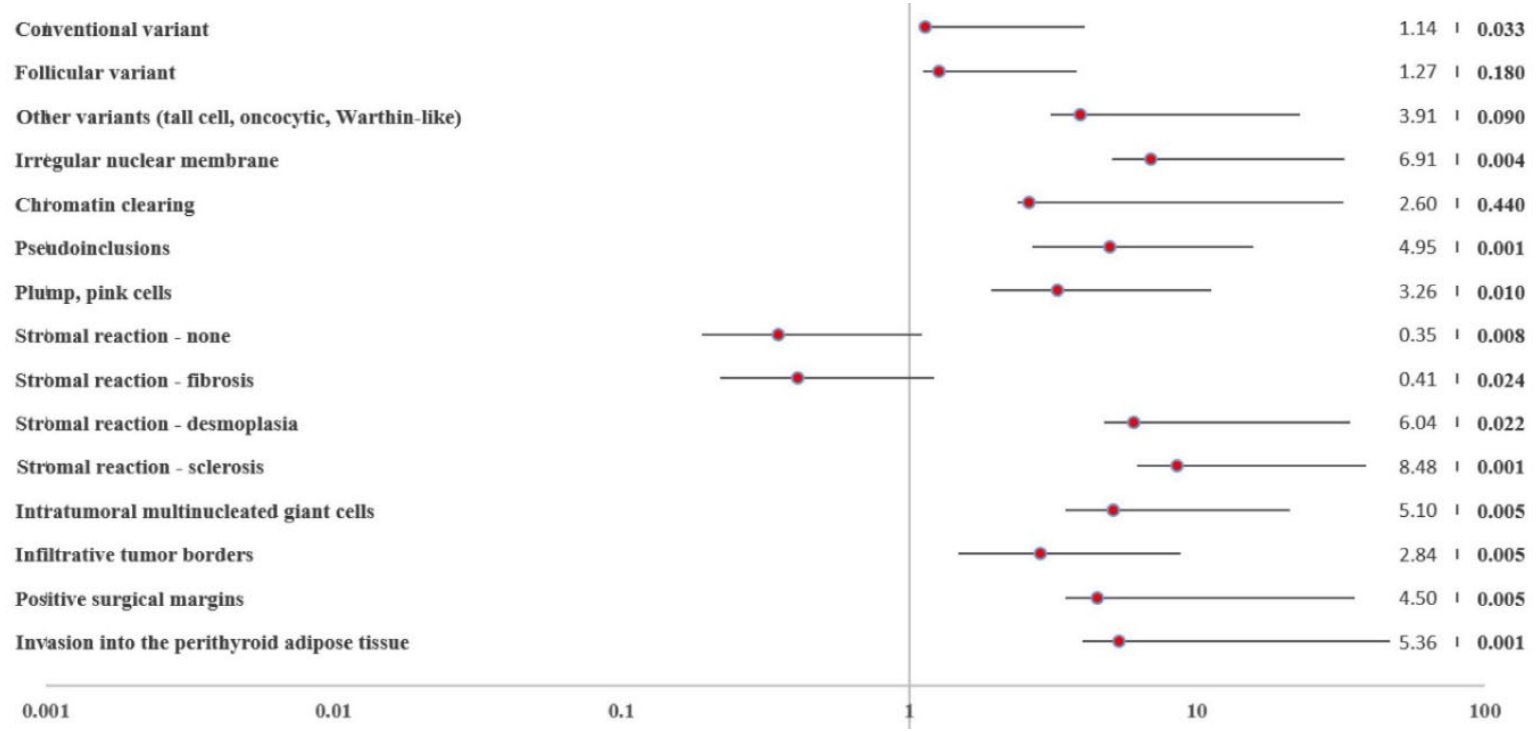

Figure 2 - Multivariate analysis comparing the four microcarcinoma groups (using Group IV as the reference for statistical analysis). The concept of this figure was inspired from the publication by Tallini et al. (2020) [13].

By contrast, Group IV PTMCs were significantly less likely than Group I PTMCs to exhibit high-grade morphological features, such as irregular nuclear membranes $(p=0.004)$ and pseudoinclusions $(p=0.001)$, and presence of plump pink cells $(p=0.010)$, tumor desmoplasia $(p=0.022)$, and sclerosis $(p=0.001)$ (Table 4$)$.

Analysis of PTMCs in Group II revealed an independent association with conventional histology $(p=0.001)$ and infiltrative tumor borders $(p=0.002)$ (Table 4$)$. Compared to PTMCs in Group I, these cases exhibited significantly fewer tumor-associated reactions $(p=0.004)$ and plump pink cells $(p=0.041)$ and significantly less nuclear chromatin clearing $(p=0.035)$

PTMCs from Group III were significantly less likely to be associated with positive resection margins $(p<0.001)$ and follicular histology $(p<0.001)$ than those in Group IV and with nuclear pseudoinclusions $(p=0.020)$ than those in Group I (Table 3 and 4).

\section{Discussions}

PTMCs are generally indolent tumors harboring an excellent prognosis $[18,21]$. Despite this, data in the literature indicate that PTMCs may include at least two biologically different subpopulations: a large group comprising tumors that are at a minimal or no risk of progression, which could benefit from active surveillance instead of immediate surgery, and a small group that includes cases with a potentially aggressive course [29]. This dual behavior of PTMCs has gradually captured the attention of many researchers aiming to identify as accurately as possible those risk factors that are associated with or could predict a high-risk PTMC phenotype (tumor persistence or recurrence, development of lymph node metastasis). Distinguishing those PTMCs that will cause significant disease from those that will cause no harm to the patient would be of exceptional clinical value: patients who require more aggressive treatment could be selected and separated from most patients with PTMC who should be spared overtreatment [29]. Male gender $[30,31]$, age $<45$ [30] or $<50$ [32] years old, tumor size $>5 \mathrm{~mm}[31,33]$, subcapsular tumor location [13, 32], multifocality [24, 34], aggressive histological variants of PTC (e.g., tall cell, oncoytic, hobnail) [35-37], extracapsular invasion $[30,31,33,38]$, poorly defined tumor borders, tumor-associated stromal reactions (fibrosis, desmoplasia, and/or sclerosis), and the presence of plump pink cells [22] have been shown to be predictors of high risk in PTMC. However, information on most of these variables is available only after surgery.

Our study aimed to determine whether two parameters that can be clinically assessed, tumor size $(\geq 5 \mathrm{~mm}$ versus $<5$ $\mathrm{mm}$ ) and location within the thyroid (subcapsular versus nonsubcapsular), could be used for the risk stratification of patients with PTMC. Based on these two parameters and by applying the methodology of Tallini et al. [13], we divided our series of 164 cases into four PTMC groups. Clinical, pathological, and follow-up data were assessed and compared between these four groups by univariate and multivariate analysis to estimate their possible relevance for risk stratification of the patients. Our results have highlighted important differences between the four PTMC groups.

Group I PTMCs (large $\geq 5 \mathrm{~mm}$, subcapsular) were strongly associated with high-grade morphological features, such as tumor desmoplasia $(p=0.022)$ and sclerosis ( $p=0.001)$, infiltrative tumor borders $(p=0.005)$, tumor invasion into the perithyroid adipose tissue $(p=0.001)$, positive surgical resection margins $(p=0.005)$, and irregular nuclear membranes $(p=0.04)$ and pseudoinclusions $(p=0.001)$. 
Although statistical significance was not reached, PTC variants such as the tall cell, oncocytic, and Warthin-like variants were more likely to be found in Group I than in the other groups. Assessment of lymph node metastasis revealed that three out of the four PTMCs with documented positive lymph node involvement had been classified as Group I. However, we did not observe statistically significant differences between Group I and other groups, most likely due to the small number of patients who underwent lymph node dissection in our study. During the follow-up period, the only patient with an unfavorable event (persistent disease) had a PTMC that had been classified as Group I.

While aggressive morphological features were highly prevalent among Group I PTMCs, at the other end of the spectrum Group IV PTMCs (small $<5 \mathrm{~mm}$, nonsubcapsular) revealed a completely different morphological profile. Almost half of cases $(47.3 \%)$ were PTMCs, follicular variant. Group IV PTMCs were characterized by a paucity of plump pink cells $(p=0.010)$; of high-grade nuclear features, such as irregular nuclear membranes $(p=0.004)$ or pseudoinclusions $(p=0.001)$; and of tumor desmoplasia $(p=0.022)$ and sclerosis $(p=0.001)$. No patients with Group IV PTMCs had lymph node metastasis.

Plump cell morphology first came to prominence as a morphological feature predictive of poor prognosis in PTCs in 2013 following the publication of a study by Virk et al. [22]. Our results revealed a high prevalence of plump pink cells among Group I PTMCs and a scarcity of these cells among Group IV PTMCs, highlighting the different tumor phenotype of the two PTMC groups.

The assessment of the tumor (T) stage in thyroid cancer has suffered significant changes according to the 2017 American Joint Committee on Cancer/Union for International Cancer Control (AJCC/UICC) TNM Classification of Tumors of Endocrine Organs [39]. Extrathyroidal extension is no longer defined as limited tumor extension into perithyroid adipose tissue only; gross extension into strap muscles is needed for a tumor to be considered extrathyroidal. For PTMC, tumor extension into the strap muscles remains rarely or even never documented, mainly due to the small tumor size [40]. By contrast, tumor invasion into the perithyroid adipose tissue can be seen in peripherally located tumors. In our study, it was significantly more prevalent among Group I PTMCs (large $>5 \mathrm{~mm}$, subcapsular), highlighting their more aggressive behavior.

Group II (large $\geq 5 \mathrm{~mm}$, nonsubcapsular) and III (small $<5 \mathrm{~mm}$, subcapsular) PTMCs exhibited morphological features between those of Group I and Group IV PTMCs. According to univariate and multivariate logistic regression, Group II and III PTMCs displayed lower risk features than did Group I PTMCs. Group II PTMCs were typically of a conventional histotype and were significantly less likely to display tumor-associated stromal reactions, plump pink cells, and nuclear chromatin clearing than Group I PTMCs. Group III PTMCs did not feature nuclear pseudoinclusions or positive resection margins.

Both the tumor size and the tumor's site of origin relating to the thyroid surface can easily be measured by neck US examination, allowing preoperative stratification of PTMCs into the one of the abovementioned groups. Thus, this easy-to-use system of dividing PTMCs into four risk groups could help in refining the selection of thyroid nodules for FNA, surgery, or active surveillance. Moreover, it could play a role in lowering the rate of overdiagnosis and overtreatment of patients with PTMC.

Some limitations of our study are also important to be considered. First, its retrospective character. However, this enabled us to obtain long-term follow-up data that, in accordance with data from the literature [18], demonstrates the indolent biological behavior of PTMCs in our series; only one patient experienced an adverse event during the follow-up period. Second, we could not evaluate lymph node involvement, an important morphological parameter, with optimal accuracy, as in our study only a limited number of patients with PTMC had undergone lymph node dissection. This is mainly because the diagnosis of cancer was made only after surgery for most patients in our study.

\section{ㅁ Conclusions}

Tumor size and location within the thyroid are two important, clinically accessible parameters that correlate with specific clinicopathological factors, enabling easy fourgroup risk subdivision of PTMC cases. This subdivision of PTMCs could have a clinical impact on the preoperative assessment of subcentimeter thyroid nodules. Our results have shown that a closer, more attentive follow-up and management is justified for large ( $\geq 5 \mathrm{~mm}$ ) subcapsular tumors, since they seem to be associated with high-grade morphological features. By contrast, most other PTMCs, and in particular those that are small $(<5 \mathrm{~mm})$ and nonsubcapsular, may be considered appropriate candidates for active surveillance programs. However, further larger studies with long-term follow-up data are needed to confirm these results.

\section{Conflict of interests}

The authors declare no conflict of interests.

\section{Acknowledgments}

The manuscript has been revised for English by an independent scientific language editing service (Anglo Scribe).

\section{References}

[1] Cramer JD, Fu P, Harth KC, Margevicius S, Wilhelm SM. Analysis of the rising incidence of thyroid cancer using the Surveillance, Epidemiology and End Results national cancer data registry. Surgery, 2010, 148(6):1147-1152; discussion 1152-1153. https://doi.org/10.1016/j.surg.2010.10.016 PMID: 21134545

[2] Davies L, Welch HG. Current thyroid cancer trends in the United States. JAMA Otolaryngol Head Neck Surg, 2014, 140(4):317-322. https://doi.org/10.1001/jamaoto.2014.1 PMID: 24557566

[3] Rovira A, Nixon IJ, Simo R. Papillary microcarcinoma of the thyroid gland: current controversies and management. Curr Opin Otolaryngol Head Neck Surg, 2019, 27(2):110116. https://doi.org/10.1097/MOO.0000000000000520 PMID: 30844924

[4] Hughes DT, Haymart MR, Miller BS, Gauger PG, Doherty GM. The most commonly occurring papillary thyroid cancer in the United States is now a microcarcinoma in a patient older than 45 years. Thyroid, 2011, 21(3):231-236. https://doi.org/10. 1089/thy.2010.0137 PMID: 21268762

[5] Pacini F. Thyroid microcarcinoma. Best Pract Res Clin Endocrinol Metab, 2012, 26(4):421-429. https://doi.org/10.1016/ j.beem.2012.07.001 PMID: 22863385 
[6] Davies L, Welch HG. Increasing incidence of thyroid cancer in the United States, 1973-2002. JAMA, 2006, 295(18):21642167. https://doi.org/10.1001/jama.295.18.2164 PMID: 16684987

[7] Kaliszewski K, Zubkiewicz-Kucharska A, Kiełb P, Maksymowicz J, Krawczyk A, Krawiec O. Comparison of the prevalence of incidental and non-incidental papillary thyroid microcarcinoma during 2008-2016: a single-center experience. World J Surg Oncol, 2018, 16(1):202. https://doi.org/10.1186/s12957-018 -1501-8 PMID: 30305094 PMCID: PMC6180613

[8] Vaccarella S, Franceschi S, Bray F, Wild CP, Plummer M, Dal Maso L. Worldwide thyroid-cancer epidemic? The increasing impact of overdiagnosis. N Engl J Med, 2016, 375(7):614-617. https://doi.org/10.1056/NEJMp1604412 PMID: 27532827

[9] Qi W, Shi C, Zhang P, Feng L, Wang J, Chen D. Effect of $B R A F$ V600E mutation detection of fine-needle aspiration biopsy on diagnosis and treatment guidance of papillary thyroid carcinoma. Pathol Res Pract, 2020, 216(8):153037. https:// doi.org/10.1016/j.prp.2020.153037 PMID: 32703500

[10] Zahan AE, Nechifor Boilă A, Paşcanu I, Voidăzan S, Cătană R Fişus A, Borda A. Papillary thyroid microcarcinomas: a 25 years retrospective, institutional study of 255 cases. Acta Marisiensis Seria Medica, 2016, 62(1):41-46. https://doi.org/ 10.1515/amma-2015-0108

[11] Ahn HS, Kim HJ, Welch HG. Korea's thyroid-cancer "epidemic" - screening and overdiagnosis. N Engl J Med, 2014, 371(19): 1765-1767. https://doi.org/10.1056/NEJMp1409841 PMID: 25372084

[12] Morris LGT, Sikora AG, Tosteson TD, Davies L. The increasing incidence of thyroid cancer: the influence of access to care. Thyroid, 2013, 23(7):885-891. https://doi.org/10.1089/thy.2013. 0045 PMID: 23517343 PMCID: PMC3704124

[13] Tallini G, De Leo A, Repaci A, de Biase D, Bacchi Reggiani ML, Di Nanni D, Ambrosi F, Di Gioia C, Grani G, Rhoden KJ, Solaroli E, Monari F, Filetti S, Durante C. Does the site of origin of the microcarcinoma with respect to the thyroid surface matter? A multicenter pathologic and clinical study for risk stratification. Cancers (Basel), 2020, 12(1):246. https://doi.org/ 10.3390/cancers12010246 PMID: 31963890 PMCID: PMC 7016743

[14] Welch HG, Black WC. Overdiagnosis in cancer. J Natl Cancer Inst, 2010, 102(9):605-613. https://doi.org/10.1093/jnci/djq099 PMID: 20413742

[15] Tallini G, de Biase D, Durante C, Acquaviva G, Bisceglia M, Bruno R, Bacchi Reggiani ML, Casadei GP, Costante G, Cremonini N, Lamartina L, Meringolo D, Nardi F, Pession A, Rhoden KJ, Ronga G, Torlontano M, Verrienti A, Visani M, Filetti S. BRAF V600E and risk stratification of thyroid microcarcinoma: a multicenter pathological and clinical study. Mod Pathol, 2015, 28(10):1343-1359. https://doi.org/10.1038/mod pathol.2015.92 PMID: 26271724

[16] Xiang T, Yan W, Zhou L. Retrospective analysis of prognostic factors in patients of papillary thyroid microcarcinoma. Oncotarget, 2018, 9(85):35553-35558. https://doi.org/10.18632/ oncotarget.26248 PMID: 30473750 PMCID: PMC6238975

[17] Ito $Y$, Miyauchi A. Active surveillance as first-line management of papillary microcarcinoma. Annu Rev Med, 2019 70:369-379. https://doi.org/10.1146/annurev-med-051517125510 PMID: 30230964

[18] Haugen BR, Alexander EK, Bible KC, Doherty GM, Mandel SJ, Nikiforov YE, Pacini F, Randolph GW, Sawka AM, Schlumberger M, Schuff KG, Sherman SI, Sosa JA, Steward DL, Tuttle RM, Wartofsky L. 2015 American Thyroid Association Management Guidelines for adult patients with thyroid nodules and differentiated thyroid cancer: The American Thyroid Association Guidelines Task Force on thyroid nodules and differentiated thyroid cancer. Thyroid, 2016, 26(1):1-133. https:// doi.org/10.1089/thy.2015.0020 PMID: 26462967 PMCID: PMC4739132

[19] Miyauchi A. Clinical trials of active surveillance of papillary microcarcinoma of the thyroid. World J Surg, 2016, 40(3): 516-522. https://doi.org/10.1007/s00268-015-3392-y PMID: 26744340 PMCID: PMC4746213

[20] Pérez-Soto RH, Velázquez-Fernández D, Arellano-Gutiérrez G, Chapa-Ibargüengoitia $M$, Trolle-Silva $A M$, Iñiguez-Ariza $N$, Pérez-Enríquez B, Sierra-Salazar M, Pantoja Millán JP, Herrera MF. Preoperative and postoperative risk stratification of thyroid papillary microcarcinoma: a comparative study between Kuma Criteria and 2015 American Thyroid Association
Guidelines Risk Stratification. Thyroid, 2020, 30(6):857-862. https://doi.org/10.1089/thy.2019.0698 PMID: 32031061

[21] Lloyd RV, Osamura RY, Klöppel G, Rosai J (eds). World Health Organization (WHO) Classification of tumours of endocrine organs. $4^{\text {th }}$ edition, International Agency for Research on Cancer (IARC) Press, Lyon, France, 2017, 65-142. https:// publications.iarc.fr/Book-And-Report-Series/Who-ClassificationOf-Tumours/WHO-Classification-Of-Tumours-Of-EndocrineOrgans-2017

[22] Virk RK, Van Dyke AL, Finkelstein A, Prasad A, Gibson J, Hui $P$, Theoharis CG, Carling T, Roman SA, Sosa JA, Udelsman $\mathrm{R}$, Prasad ML. BRAF ${ }^{\mathrm{V} 600 \mathrm{E}}$ mutation in papillary thyroid microcarcinoma: a genotype-phenotype correlation. Mod Pathol, 2013, 26(1):62-70. https://doi.org/10.1038/mod pathol.2012.152 PMID: 22918165

[23] Nikiforov YE, Seethala RR, Tallini G, Baloch ZW, Basolo F, Thompson LDR, Barletta JA, Wenig BM, Al Ghuzlan A, Kakudo K, Giordano TJ, Alves VA, Khanafshar E, Asa SL, El-Naggar AK, Gooding WE, Hodak SP, Lloyd RV, Maytal G, Mete O, Nikiforova MN, Nosé V, Papotti M, Poller DN, Sadow PM, Tischler AS, Tuttle RM, Wall KB, LiVolsi VA, Randolph GW, Ghossein RA. Nomenclature revision for encapsulated follicular variant of papillary thyroid carcinoma: a paradigm shift to reduce overtreatment of indolent tumors. JAMA Oncol, 2016, 2(8):1023-1029. https://doi.org/10.1001/ jamaoncol.2016.0386 PMID: 27078145 PMCID: PMC5539411

[24] Xu D, Lv X, Wang S, Dai W. Risk factors for predicting central lymph node metastasis in papillary thyroid microcarcinoma. Int J Clin Exp Pathol, 2014, 7(9):6199-6205. PMID: 25337270 PMCID: PMC4203241

[25] Zheng X, Peng C, Gao M, Zhi J, Hou X, Zhao J, Wei X, Chi J, Li D, Qian B. Risk factors for cervical lymph node metastasis in papillary thyroid microcarcinoma: a study of 1,587 patients. Cancer Biol Med, 2019, 16(1):121-130. https://doi.org/10. 20892/j.issn.2095-3941.2018.0125 PMID: 31119052 PMCID: PMC6528461

[26] Finkelstein A, Levy GH, Hui P, Prasad A, Virk R, Chhieng DC, Carling T, Roman SA, Sosa JA, Udelsman R, Theoharis CG, Prasad ML. Papillary thyroid carcinomas with and without BRAF V600E mutations are morphologically distinct. Histopathology, 2012, 60(7):1052-1059. https://doi.org/10.1111/ j.1365-2559.2011.04149.x PMID: 22335197

[27] Rosai J, DeLellis RA, Carcangiu ML, Frable WJ, Tallini G. Tumors of the thyroid and parathyroid glands. $4^{\text {th }}$ edition, Armed Forces Institute of Pathology (AFIP) Atlas of Tumor Pathology, $4^{\text {th }}$ Series, Fascicle 21, American Registry of Pathology, Silver Spring, Maryland, USA, 2014, 1-493. https:// www.worldcat.org/title/tumors-of-the-thyroid-and-parathyroidglands/oclc/904183558

[28] American Thyroid Association (ATA) Guidelines Taskforce on Thyroid Nodules and Differentiated Thyroid Cancer; Cooper DS, Doherty GM, Haugen BR, Kloos RT, Lee SL, Mandel SJ, Mazzaferri EL, Mclver B, Pacini F, Schlumberger M, Sherman SI, Steward DL, Tuttle RM. Revised American Thyroid Association management guidelines for patients with thyroid nodules and differentiated thyroid cancer. Thyroid, 2009, 19(11):1167-1214. https://doi.org/10.1089/thy.2009.0 110 PMID: 19860577

[29] Rodrigues AC, Penna G, Rodrigues E, Castro P, SobrinhoSimões M, Soares $P$. The genetics of papillary microcarcinomas of the thyroid: diagnostic and prognostic implications. Curr Genomics, 2017, 18(3):244-254. https://doi.org/10.2174/ 1389202918666170105094459 PMID: 28659720 PMCID: PMC5476952

[30] Lin DZ, Qu N, Shi RL, Lu ZW, Ji QH, Wu WL. Risk prediction and clinical model building for lymph node metastasis in papillary thyroid microcarcinoma. Onco Targets Ther, 2016, 9:5307-5316. https://doi.org/10.2147/OTT.S107913 PMID: 27601922 PMCID: PMC5004998

[31] Kim SK, Park I, Woo JW, Lee JH, Choe JH, Kim JH, Kim JS. Predictive factors for lymph node metastasis in papillary thyroid microcarcinoma. Ann Surg Oncol, 2016, 23(9):28662873. https://doi.org/10.1245/s10434-016-5225-0 PMID: 27075321

[32] Jeon MJ, Chung MS, Kwon H, Kim M, Park S, Baek JH, Song DE, Sung TY, Hong SJ, Kim TY, Kim WB, Shong YK, Lee JH, Kim WG. Features of papillary thyroid microcarcinoma associated with lateral cervical lymph node metastasis. Clin 
Endocrinol (Oxf), 2017, 86(6):845-851. https://doi.org/10.1111/ cen.13322 PMID: 28273370

[33] Zhao C, Jiang W, Gao Y, Niu W, Zhang X, Xin L. Risk factors for lymph node metastasis (LNM) in patients with papillary thyroid microcarcinoma (PTMC): role of preoperative ultrasound. $\mathrm{J}$ Int Med Res, 2017, 45(3):1221-1230. https://doi.org/10. 1177/0300060517708943 PMID: 28534700 PMCID: PMC 5536411

[34] Yan L, Blanco J, Reddy V, Al-Khudari S, Tajudeen B, Gattuso P. Clinicopathological features of papillary thyroid microcarcinoma with a diameter less than or equal to $5 \mathrm{~mm}$. Am J Otolaryngol, 2019, 40(4):560-563. https://doi.org/10.1016/j.amjoto.2019. 05.003 PMID: 31103218

[35] Mercante G, Frasoldati A, Pedroni C, Formisano D, Renna L, Piana S, Gardini G, Valcavi R, Barbieri V. Prognostic factors affecting neck lymph node recurrence and distant metastasis in papillary microcarcinoma of the thyroid: results of a study in 445 patients. Thyroid, 2009, 19(7):707-716. https://doi. org/10.1089/thy.2008.0270 PMID: 19348581

[36] Durante C, Attard M, Torlontano M, Ronga G, Monzani F, Costante G, Ferdeghini M, Tumino S, Meringolo D, Bruno R, De Toma G, Crocetti U, Montesano T, Dardano A, Lamartina L, Maniglia A, Giacomelli L, Filetti S; Papillary Thyroid Cancer Study Group. Identification and optimal postsurgical follow-up of patients with very low-risk papillary thyroid microcarcinomas.
J Clin Endocrinol Metab, 2010, 95(11):4882-4888. https:// doi.org/10.1210/jc.2010-0762 PMID: 20660054

[37] Kazaure HS, Roman SA, Sosa JA. Aggressive variants of papillary thyroid cancer: incidence, characteristics and predictors of survival among 43,738 patients. Ann Surg Oncol, 2012, 19(6):1874-1880. https://doi.org/10.1245/s10434-011 -2129-x PMID: 22065195

[38] Zhang L, Wei WJ, Ji QH, Zhu YX, Wang ZY, Wang Y, Huang $C P$, Shen $Q$, Li DS, Wu Y. Risk factors for neck nodal metastasis in papillary thyroid microcarcinoma: a study of 1066 patients. J Clin Endocrinol Metab, 2012, 97(4):12501257. https://doi.org/10.1210/jc.2011-1546 PMID: 22319042

[39] Brierley JD, Gospodarowicz MK, Wittekind C (eds). TNM Classification of malignant tumors. $8^{\text {th }}$ edition, Union for International Cancer Control (UICC), John Wiley \& SonsBlackwell, Oxford, UK, 2017, 51-55. https://www.wiley.com/ en-ad/TNM+Classification+of+Malignant+Tumours\%2C+8th +Edition-p-9781119263579

[40] Lee WK, Lee J, Kim H, Lee SG, Choi SH, Jeong S, Kwon HJ, Jung SG, Jo YS. Peripheral location and infiltrative margin predict invasive features of papillary thyroid microcarcinoma. Eur J Endocrinol, 2019, 181(2):139-149. https://doi.org/10. 1530/EJE-18-1025 PMID: 31146263

\section{Corresponding author}

Adela Corina Nechifor-Boilă, MD, PhD, Department of Histology, George Emil Palade University of Medicine, Pharmacy, Science, and Technology of Târgu Mureş, 38 Gheorghe Marinescu Street, 540139 Târgu Mureş, Romania; Phone +40746-320 025 (Mobile), +40265-215 551 (int. 152), Fax +40265-210 407, e-mail: adela.nechifor-boila@umfst.ro 